\title{
The effects of building layouts and envelope on indoor thermal environment of Hui style traditional buildings in Wuyuan
}

\author{
Xiaowei Hong ${ }^{1, *}$, Guangjin Zhang ${ }^{2}$, Yufeng Zhang ${ }^{3}$ \\ ${ }^{1}$ Xiamen Academy of Building Research co. LTD, 361004, China; \\ ${ }^{2}$ Wuyuan Meteorological Bureau, Wuyuan, Shangrao 333200, China; \\ ${ }^{3}$ South China University of Technology, Tianhe, Guangzhou 510640, China;
}

\begin{abstract}
Indoor thermal environment of Hui style traditional houses is depended on surrounding environments, building layouts and envelope. Quantitative analysis of the effects of building layouts and envelope on indoor thermal environment is of great significance for preventions of traditional houses and design of new archaized houses. A field investigation was conducted on thirty-six traditional houses from nine villages in Wuyuan, and the typical buildings' layout and envelope were determined. Four traditional buildings in different location in Wuyuan were selected for continual recording. The four buildings with four types of building layouts and envelope were analyzed by using local adaptive thermal comfort model, and the effects of building layouts and envelope of traditional buildings were clearly revealed. The most crucial way to improve indoor thermal environment in Hui style traditional buildings was raising the indoor air temperature.
\end{abstract}

\section{Introduction}

When the number of housing rapidly demanded and constructed, the requirements on housing comfort are also improved. If the architecture can extract and use the fine design strategies of traditional buildings, it will help to cut down expense, save resources, and design sustainable buildings.

Observation, the field investigation on the natural ventilated traditional buildings is the necessary methods to extract the strategies which can improve the thermal comfort in traditional buildings. By using the local adaptive thermal comfort model, the changes of indoor thermal environment and the factors those influenced the changes can be determined, the relationship between them then can be quantified.

\section{Investigation and recording}

\subsection{Methods}

We take the Hui style traditional buildings in Wuyuan as the researching objects. Wuyuan is located in the northeast of Jiangxi Province $\left(117^{\circ} 51\right.$ E, $\left.29^{\circ} 16 \mathrm{~N}\right)$, the subtropical monsoon climate and the hot summer - cold winter area in China[1].

Table 1. The layout of Hui style traditional buildings and the number of different layouts
In March 2014, the author conducted an investigation on thirty-six traditional buildings from nine villages in Wuyuan and selected four of them for continued records from March to October. The basic information and the thermal environment of buildings were obtained by investigation and recording.

\subsection{Basic information}

The layout of Hui style traditional buildings was characterized by patios, which influenced the natural ventilation and daylighting. The styles of building layouts[2] were classified into two classifications(Basic type and Combined type) and 13 kinds depending on patios as shown in the Table 1, which named by Chinese words, such as “四”, “一”, “凹”, “口”, “回”. These layouts were the main part of building and did not include the yards, $2 / 3$ of traditional buildings had two patios, and some buildings had only one patio because of demolishing. The main part buildings were almost two stories about $8 \sim 10 \mathrm{~m}$ high, the yards were not big and always located on the south of buildings. Around the buildings were also buildings or narrow alleyways, and the windows were few and small, so it were hard for the rooms to receive the sunlight.

\begin{tabular}{|l|l|}
\hline Classification & Kinds \\
\hline
\end{tabular}

\footnotetext{
* Corresponding author: 1967971020@qq.com
} 


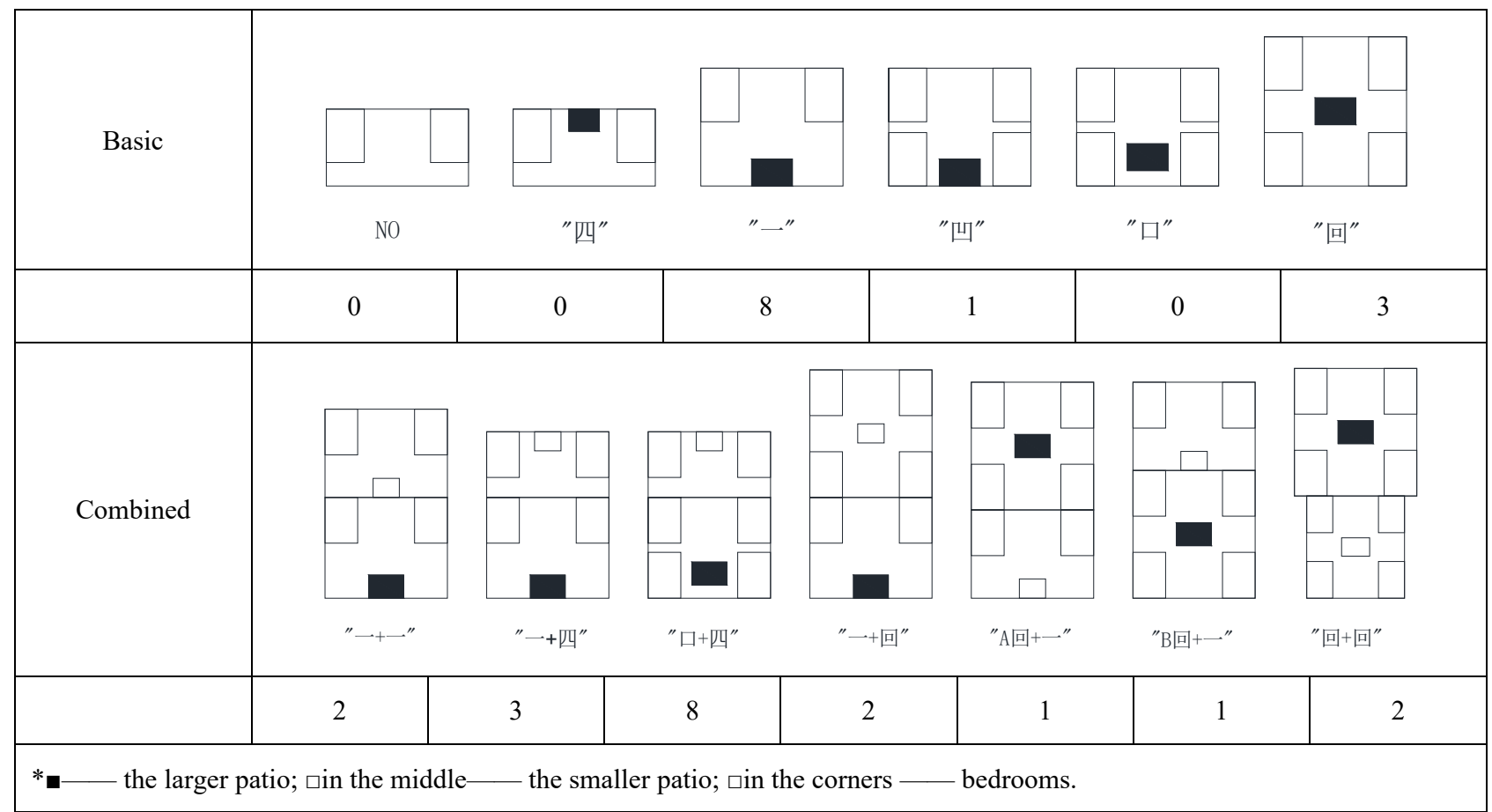

The building envelope was another important information used to analyse the indoor thermal environment. The constructions of roofs, floors, and interior walls in each building were same as other traditional buildings. The roof was a smooth slope with a $1.5 \mathrm{~m}$ eave towards the patio, built by using wood strips and thin bricks, and the floors and interior walls both were made of wood strips just as the deck. On the other hand,

a

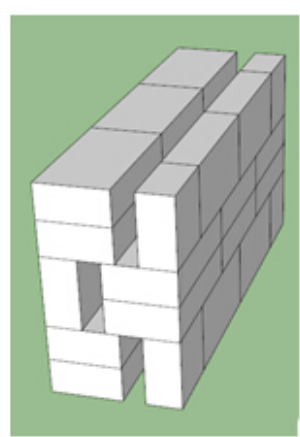

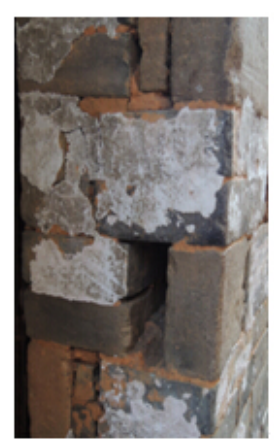

the exterior walls were different between each building on the respects of thickness and construction. There were two main kinds of exterior walls, which named “两平一 侧"(Two horizontal bricks and one vertical brick in each layer, TO for short) and “一眠一斗”(One horizontal bricks and Two vertical cross brick in each layer, OTC for short), and shown in the Fig. 1.
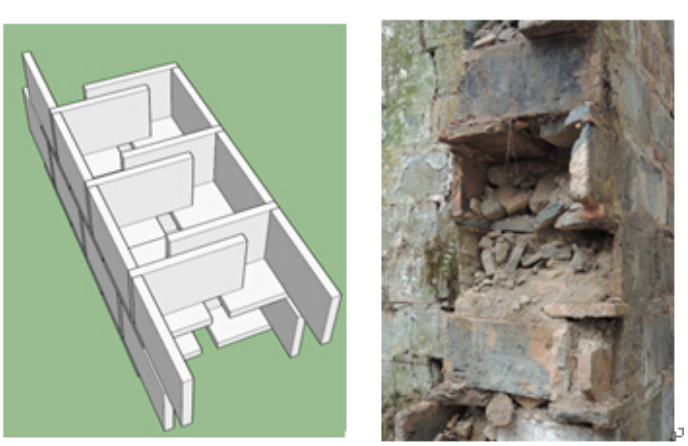

Fig. 1. "TO"(a) and "OTC"(b)

Both of them were made of grey bricks and yellow clay, but the sizes of brick and the structures of wall were different. In order to compare the different function of walls, it is necessary to calculate the thermal resistance. The range of thermal resistance and $\mathrm{K}$-value were listed in the Table 2.

Table 2. Thermal parameters of two kinds of wall

\begin{tabular}{|c|c|c|}
\hline Name & "TO" & "OTC" \\
\hline Thickness (m) & $0.23 \sim 0.30$ & $0.30 \sim 0.40$ \\
\hline Size of brick (m) & $0.25 * 0.15 * 0.60$ & $0.24 * 0.15 * 0.20$ \\
\hline Brick K $\left(\mathrm{m}^{2} \cdot \mathrm{K} / \mathrm{W}\right)[3]$ & 0.65 & 0.65 \\
\hline Air Gap $(\mathrm{m})[4]$ & $0.02 \sim 0.09$ & $0.01 \sim 0.10$ \\
\hline
\end{tabular}




\begin{tabular}{|c|c|c|}
\hline Plastering $\mathrm{K}\left(\mathrm{m}^{2} \cdot \mathrm{K} / \mathrm{W}\right)[3]$ & 0.15 & 0.15 \\
\hline External+Interial $\mathrm{R}\left(\mathrm{m}^{2} \cdot \mathrm{K} / \mathrm{W}\right)[4]$ & 0.16 & 0.16 \\
\hline Wall $\mathrm{R}\left(\mathrm{m}^{2} \cdot \mathrm{K} / \mathrm{W}\right)$ & $0.68 \sim 0.69$ & $0.66 \sim 0.83$ \\
\hline Wall $\mathrm{K}\left(\mathrm{W} /\left(\mathrm{m}^{2} \cdot \mathrm{K}\right)\right)$ & $1.45 \sim 1.47$ & $1.20 \sim 1.52$ \\
\hline
\end{tabular}

There were four buildings selected for data recording. The main different basic building information between each other was shown in the Table 3. The record instruments (HOBO Pro v2 logger U23-002) were put in their bedrooms and halls, shown as the Fig. 2.

Table 3. Basic building information of four buildings

\begin{tabular}{|c|c|c|c|c|}
\hline Location & HG & LK & YC & WK \\
\hline Building orientation & $\mathrm{S}$ & $\mathrm{E}$ & $\mathrm{S}$ & $\mathrm{S}$ \\
\hline Layouts & $\mathrm{A}$ 回+一 & 一 & 口+四 & 一 \\
\hline Adjacent buildings & ESW & ESW & $\mathrm{S}$ & ESW \\
\hline Wall Construction & $\mathrm{b}$ & $\mathrm{b}$ & $\mathrm{b}$ & $\mathrm{a}$ \\
\hline Wall R (m²K/W) & 0.75 & 0.77 & 0.73 & 0.69 \\
\hline Hall Height (m) & 4.7 & 3.5 & 4.4 & 4.5 \\
\hline Hall Width (m) & 4.8 & 4.1 & 4.2 & 4 \\
\hline Area of Bedroom $\left(\mathrm{m}^{2}\right)$ & 9.6 & 12.3 & 13.7 & 7.9 \\
\hline Area of Patio $\left(\mathrm{m}^{2}\right)$ & 5.6 & 5.7 & 10.1 & 7.4 \\
\hline
\end{tabular}

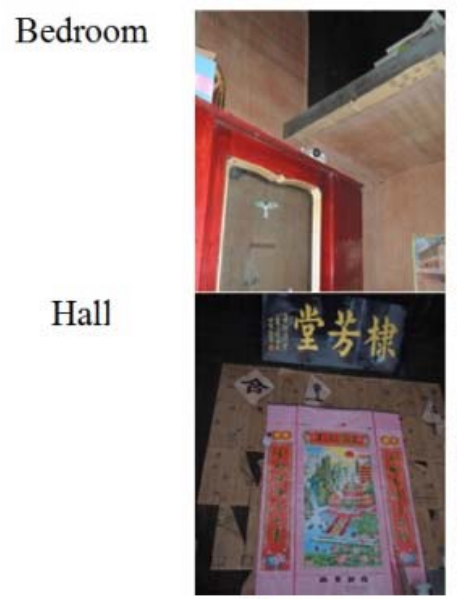

Hongguan

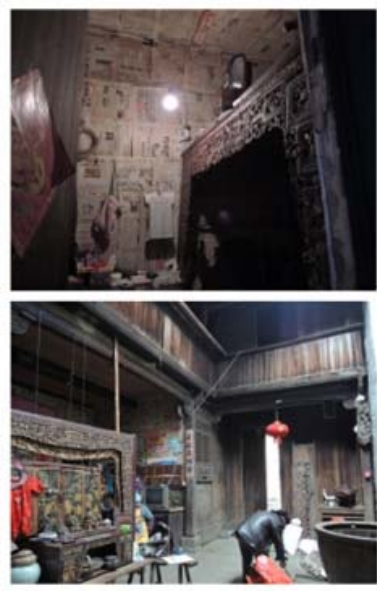

Likeng
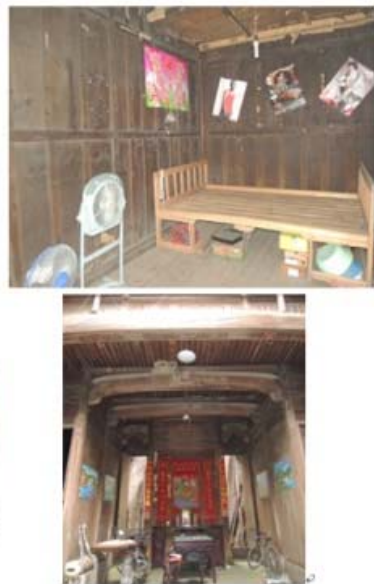

Yancun
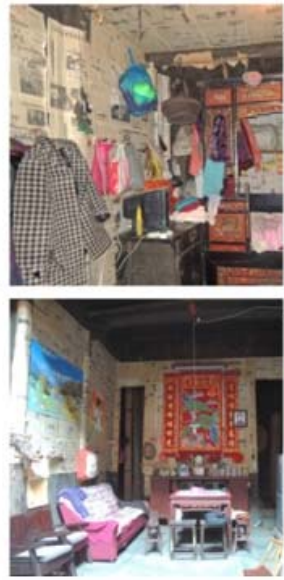

Wangkou

Fig. 2. The instruments in bedrooms and halls of four buildings

2.3 Outdoor air temperature and indoor air temperature
To evaluate the indoor thermal environment, this paper use the adaptive thermal comfort model, so the air temperature was the only data used. By continual recods, the air temperature of bedrooms, halls and patios were 
obtained. The outdoor air temperature provide by local weather bureau.

There were only three seasons in Wuyuan from March to October 2014, and the season divided by mean temperature of every five days. In 2014, the spring started on 11th March, the summer started on 11th May and the autumn started on 6th October[5]. The outdoor temperature was shown as in the Fig. 3.

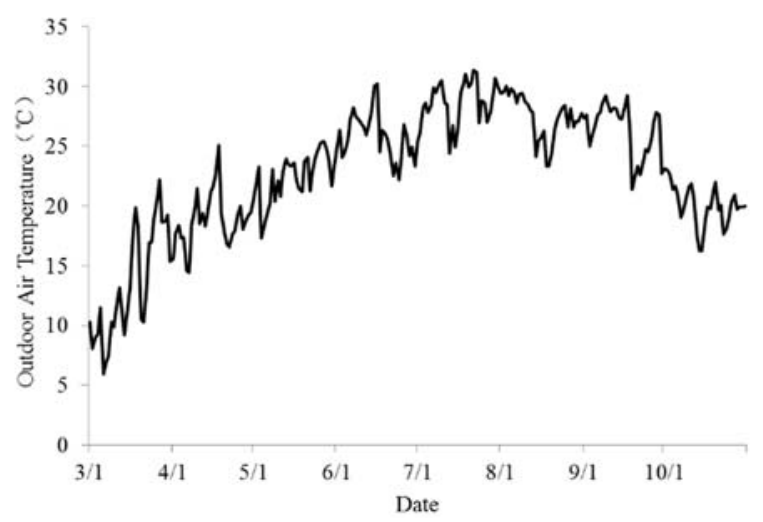

Fig. 3. Average day outdoor air temperature from March to October 2014

\section{Adaptive thermal comfort model}

Because Wuyuan located in the hot summer - cold winter area in China, it will be more reasonable to use the adaptive model which was propounded based on the data nearby instead of the regular one. After collecting the data of field tests from several places in the same area, the data from natural ventilated buildings in Hubei and Shanghai was selected for analysis. There were 3222 sets of efficient data all together including date, time, thermal sensation vote and air temperature. This model was similar to that in ASHRAE 55 [6,7], it was the linear regression equation between indoor neutral temperature(The regression of thermal sensation votes and indoor air temperature weighted by sample size) and mean outdoor temperature(The average temperature of each month based on CSWD ), see equation (1). and Fig. 4.

$$
t_{\text {com }}=0.26 t_{(o u t, m)}+19.9\left(R^{2}=0.50\right)
$$

$t_{\text {com }}$ - Indoor neutral temperature $\left({ }^{\circ} \mathrm{C}\right)$;

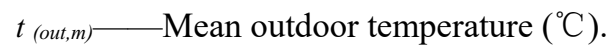

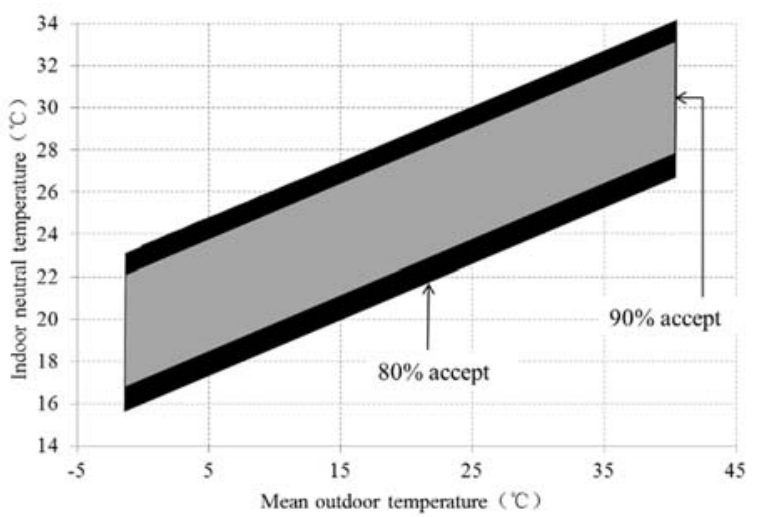

Fig. 4. The propounded adaptive thermal comfort model
Compare with the adaptive model in ASHRAE 55, the indoor neutral temperature of this propounded adaptive model was higher both in summer and in winter.

\section{Result and discussion}

The data of air temperature in four buildings was shown in the table 4, it shows the air temperature of building in $\mathrm{LK}\left(22.4^{\circ} \mathrm{C}\right.$ in the bedroom and $21.8^{\circ} \mathrm{C}$ in the hall)was higher than other three and that in $\mathrm{HG}$ was the coolest $\left(21.0^{\circ} \mathrm{C}\right.$ in the bedroom and $19.8^{\circ} \mathrm{C}$ in the hall).

Table 4. Average air temperature of four buildings

\begin{tabular}{|c|c|c|c|}
\hline Location & Bedroom $\left({ }^{\circ} \mathrm{C}\right)$ & Hall $\left({ }^{\circ} \mathrm{C}\right)$ & Patio( $\left.{ }^{\circ} \mathrm{C}\right)$ \\
\hline HG & 21.0 & 19.8 & 20.7 \\
\hline LK & 22.4 & 21.8 & 21.8 \\
\hline YC & 21.6 & 21.8 & 23.0 \\
\hline WK & 22.0 & 21.6 & 20.6 \\
\hline
\end{tabular}

Data in the period of March 11th to July 25th was analyzed by using the propounded model, the comfort hours of $80 \%$ accept in this four traditional buildings can be calculated, in addition, the overheated and overcooled hours also can be calculated. In this period, it contains the whole spring and part of summer, in different seasons, the comfort hours shown the changes.

Table 5. The comfort, overheated and overcooled hours in four traditional buildings

\begin{tabular}{|c|c|c|c|c|c|}
\hline \multirow{2}{*}{ Location } & \multirow{2}{*}{ Stata } & \multicolumn{2}{|c|}{ Spring } & \multicolumn{2}{|c|}{ Summer } \\
\hline & & B & H & B & $\mathbf{H}$ \\
\hline \multirow{3}{*}{$\mathrm{HG}$} & $\mathrm{OH}$ & 0 & 0 & 0 & 0 \\
\hline & $\mathrm{OC}$ & 749 & 1055 & 37 & 189 \\
\hline & Comfort & 11 & 9 & 573 & 665 \\
\hline \multirow{3}{*}{ LK } & $\mathrm{OH}$ & 0 & 0 & 0 & 0 \\
\hline & $\mathrm{OC}$ & 620 & 999 & 11 & 65 \\
\hline & Comfort & 140 & 65 & 599 & 789 \\
\hline \multirow{3}{*}{ YC } & $\mathrm{OH}$ & 0 & 0 & 0 & 2 \\
\hline & $\mathrm{OC}$ & 721 & 986 & 44 & 60 \\
\hline & Comfort & 39 & 78 & 566 & 792 \\
\hline \multirow{3}{*}{ WK } & $\mathrm{OH}$ & 0 & 0 & 0 & 0 \\
\hline & $\mathrm{OC}$ & 670 & 1049 & 6 & 106 \\
\hline & Comfort & 90 & 15 & 604 & 750 \\
\hline
\end{tabular}


${ }^{\text {a }} \mathrm{OH}$-Overheated; OC-Overcolded ;B-Bedroom ;H-Hall.

In Table 5, the discomfort due to overcooled except 2 hours overheated in hall of $\mathrm{YC}$, it can infer that no matter in hot summer or in cold winter, the discomfort was caused by low air temperature, and the situation was even worse in winter for its cold and wet climate. It also tells that traditional buildings were seldom comfortable in spring, autumn and winter for their low temperature, but they were almost comfortable in summer. The relative humidity in Wuyuan was always high, the outdoor average relative humidity was $76.8 \%$. Therefore, to improve the thermal environment, it required a higher indoor air temperature.

According to the whole comfortable hours from March 11th to July 25th, the bedroom in LK was most comfortable while the one in HG was most uncomfortable, the hall in $\mathrm{YC}$ was most comfortable while the one in $\mathrm{HG}$ was most uncomfortable.

Looking back at the basic traditional building information as shown in the table 3 , were about the layouts and envelope, which were the crucial factors influencing the indoor air temperature.

There were two aspects resulting warmer bedroom. On the one hand, the solar radiation on wall and roof determined the heat gained by building, while the building orientation and adjacent buildings interrupted the solar radiation. Therefore, the south towards buildings with less adjacent buildings can provide more solar radiation for the bedrooms. On the other hand, the construction of the wall was the most important envelope in traditional buildings. The thicker walls result better resistance which benefit the higher thermal insulation, and wall named "OTC" was better than wall named "TO". In the hall, receiving more solar radiation was the most important factor for the higher indoor air temperature. Larger patio next to the south outdoor with a smaller hall can result more comfort hours, causing by receiving more solar radiation. The building with “口+四” layout had largest patio next to the south outdoor.

\section{Conclusion}

Raising the indoor air temperature was the crucial way to improve the thermal environment in Hui style traditional buildings. According to the analysis as above, there were several ways to raising the air temperature as follows:

- Design bigger exterior surface of building particularly the south exterior surface of building.

- Chose the larger thermal resistance of exterior wall named "OTC" instead of the wall named "TO".

- Design smaller bedrooms.

- Design larger patio with smaller halls, such as the layout of “口+四”.

\section{Acknowledgements}

We extend our gratitude to Wuyuan weather bureau for providing the local weather data, to Professor Ye from Wuhan Institute of Technology and Professor Lian from Shanghai Jiao
Tong University for providing the valuable filed testing data, to the kindly residents in Wuyuan for their actively cooperation.

\section{References}

1. China planning press, GB 50176-93 Thermal Design Code for Civil Building, Beijing; 1993.

2. Zhaoqun, Research on the Ecological Experiences and Pattern Language of Traditional residential buildings;2004.

3. Tang Guohua, The hot-wet climate and traditional buildings in Lingnan, China Architecture \& Building Press; 2006.

4. China Academy of building research, JGJ 75-2012 Hot summer and warm winter region residential building energy-saving design standard, Guangzhou;2012.

5. Lin Guangzhi, Concern about Climate-climate and its cultural influence, China International RadioPress;2013.

6. R.de Dear, Brager, Thermal comfort in naturally ventilated buildings: revisions to ASHRAE Standard 55. 2002: 549 - 561.

7. ASHRAE Standard 55-2010, Thermal Environmental Conditions for Human Occupancy;2010. 